\title{
Newforest institute: restoring habitat for resilience and vision in the forested landscape
}

\author{
A. $\operatorname{Read}^{1}$, G. Callas ${ }^{1}$, T. Maseychik ${ }^{1}$, K. Callas ${ }^{1}$, A. Kekacs ${ }^{1}$, \\ R. Read ${ }^{2}$ \& R. J. Lilieholm ${ }^{3}$ \\ ${ }^{I}$ Newforest Institute, USA \\ ${ }^{2} C$ Change Investments, USA \\ ${ }^{3}$ University of Maine, School of Forest Resources, USA
}

\begin{abstract}
Humans have long relied on the land for their material, psychological, and spiritual well-being, understanding themselves as an integral part of the natural world. However, in modern times - and in accelerated fashion - this essential and multi-layered connection has been sorely strained if not altogether severed, resulting in poverty of both a material and spiritual nature with profound consequences not only for the environment, but also for the human community as well. Seeing the human community as an ecosystem within the landscape provides a meaningful framework for understanding its role as a powerful component of broader ecological restoration. Indeed, to restore to the human community its ability to experience itself as nature, embedded within the larger landscape, is a fundamental and indispensable act of environmental restoration. With the objective of developing means of creating measurable, landscape-scale improvements in the health and resilience of forests and forest-dependent communities, the Newforest Institute pursues three core activities: (1) community-based initiatives; (2) strategic partnering; and (3) research design and implementation. Working with university, government and community partners, we have developed the conceptual frameworks underlying the three forest-related initiatives we outline here: The Urban-Rural Youth Forestry Partnership, The Women's Earth Project, and The Abundance Project. In this paper, we outline our initiatives, research design, and alternative approaches to sustainable forest management, community-based forestry, and processes of community engagement and change.
\end{abstract}

Keywords: community forestry, resilience, food forest, forest dependency, social sculpture, permaculture, project-based learning, new forest. 


\section{Introduction}

Despite the age-old, periodic cultural devastation brought on most consistently by deforestation, perhaps only modernity is marked by the most conscious separation of man and nature heretofore experienced. Beginning with the Renaissance and intensified in the Industrial Revolution, the notion of human centrality in the universe has ushered in mankind's control over nature at an ever accelerating pace. The devastating effect on the environment by such a worldview has been recorded by intellectuals, philosophers and writers from Rousseau and later Thoreau, up through all those such as John Muir and Aldo Leopold whose work gave rise to the modern environmental movement. They recognized that our 'progress' as a civilization led to, and at the same time was born of, a detachment from the natural world that ultimately imperiled the health and viability of both the natural environment and the human soul - the inner and outer landscapes inextricably bound together in ways immeasurable by rational methods yet for most of human history the domain of the arts and religious cosmology. Once that connection had been severed, mankind would uncontrollably exploit the abundance of nature for short-term gain at the price of long-term degradation. Only now becoming palpable is the relationship between the degradation of our physical landscapes and the poverty of a socio-economic, cultural and spiritual nature that inevitably ensues.

Our objective at Newforest Institute is to restore the connection between people and nature, merging the inner and outer landscapes as a way of catalyzing systemic, long-term improvements in socio-economic, ecological, cultural and spiritual well-being. It is also our objective to create visible, landscape-scale change. How can these goals be accomplished except through the human community? Echoing the historical New Forest, established in 1079 by England's William I, our name reflects an engagement at the intersection of the human community and the natural world. It also reflects our belief that without a significant paradigm shift, that is, without a reconciliation of our inner and outer landscapes, no such systemic improvements are sustainable. With respect to the New Forest, that historical relationship between the human community and the land led to the notion of the 'commons' and the land rights outlined in the Charter of the Forest of 1217. In our time, the health of both the environment and the human community requires a similarly radical renegotiation. Just as habitat for wildlife and plant life may be destroyed or restored, so habitat for resilience and vision within the human community must be restored. In habitat restoration, the goal is to create, or recreate, those conditions by which certain kinds of life forms flourish. What we must restore now is habitat for vision specifically, the human ability to think like nature, to experience ourselves as nature in a way and on a level that leads to measurable change in our landscapes. We need a new mind for what we are trying to see. Effecting the kind of widespread and sustainable improvements we envision will most certainly require a level of collective inner transformation perhaps unprecedented in our time. 


\section{History}

The Newforest Institute was founded in 2006 as a non-profit organization dedicated to improved community and sustainable development practices grounded in a deep, revitalized connection to the natural environment. Our work is motivated by three driving forces: (1) our society's fractured approach to scientific and social 'progress,' as opposed to wholeness, has become increasingly unsustainable; (2) through integrative study, sustainable development projects and community initiatives, we can promote those practices critical to a healthy, productive and sustainable society for the future; and (3) nurturing both the individual and collective capacity for creative vision is the unassailable underpinning of any enduring transformation within the human community. The complexity and the urgency of our common future require creative leadership and visionary thinking in all sectors of society. It requires what German artist Joseph Beuys referred to as an expanded application of human creativity and the "social sculpture" that would inevitably follow, literally "re-forming" the human social, economic, and cultural systems toward an ever closer and better approximation of the beautiful. Such an enlivening requires the widespread unleashing of the capacity for creative vision, the handmaiden of resilience. Our goal is to cultivate the full spectrum of human capability rooted in a renewed relationship to the land, to the self and the larger living community.

The idea for what would become the Newforest Institute was planted in Jersey City, USA, in the 1990s with the desire of its founders - Andrea and Russell Read, and George and Kimberly Callas - and others to create an organization capable of nurturing rigorous interdisciplinary exploration that could help to usher into being significant shifts for both individuals and their communities. An initial intention was that such an institute would address the poverty, environmental degradation and fragmentation which had become characteristic of our communities. We also recognized that to restore to the human community its ability to experience itself as nature would allow us to act more often in concert with nature, creating in both the built environment and the natural world systems that would allow the human community to meet its needs in ways that promoted sustainable ecological health. Furthermore, we were united in our belief that gainful dialogue among our various fields - art, writing, documentary film, economics and finance - would inevitably be the bedrock of innovative approaches to the socio-economic, cultural and environmental challenges we were seeing in both urban and rural communities.

In 1999, Russell and Andrea bought a 75-acre farm in Brooks, Maine. The ice storm of 1998 had destroyed many trees in the region, spurring heavy harvesting on small and large forest parcels alike. The Reads purchased a 110acre piece of heavily harvested land across the road, and what began as an idea to plant a hundred trees grew over two seasons into a 10,000 hardwood tree reforestation project. In 2002, motivated by a personal examination of their ecological footprint, George and Kimberly bought 360-acres of clear-cut land in Brooks with the goal of designing and building a house and homestead that would reflect their vision of beauty and energy efficiency integrated with the 
immediate landscape. In December 2005, the acquisition of 275 acres at the edge of the rural village of Brooks, Maine became a catalyst for the creation of Newforest Institute, and the parcel expanded over the following six months to include almost 300 contiguous acres of forest, stream, fields, an old farmhouse and barns.

Newforest Institute was incorporated in May 2006 as a non-profit educational organization dedicated to restoring the mutually sustaining relationships between individuals, communities and the land. In the fall of 2009, Newforest intends to launch its Center for Urban Sustainability headquartered in a firehouse dating back to 1863, located in the heart of downtown Jersey City, New Jersey, recognizing the firehouse and its urban Jersey City community as an integral part of Newforest's own organizational and conceptual landscape.

\section{Catalyzing systemic change from the inside out}

In the beginning of The Voice of the Earth, written on the heels of the 1992 Rio Summit, Theodore Roszak reflects on the failure of the environmental movement to have significantly affected human behavior in the face of unrelenting ecological devastation, asking whether "there is an alternative to scare tactics and guilt trips that will lend ecological necessity both intelligence and passion?" "There is," Roszak [1] posits. "It is the concern that arises from shared identity; two lives that become one. Where that identity is felt deeply, we call it love...This is the link we must find between ourselves and the planet that gives us life." Indeed, love must surely be the only thing that has ever motivated enduring change. Asserting that "what the Earth requires will have to make itself felt within us as if it were our own most private desire," Roszak [2] develops the notion of the ecological ego and ecopsychology, arguing finally that "the motivation for change on a planetary scale must arise from within a genuinely personal need for a new quality of life" [3]. It is precisely such a shift in one's ability to see, and indeed to experience, one's own thriving inextricably bound with that of another - or what is perceived as 'other' - that allows us as humans to restore our ability to live and act out of a connectedness with the natural world. How, though, is such a shift possible? Or more exactly, where?

The seeds for Newforest Institute and its initiatives were planted years ago, the result of the confluence of two important impulses - a restlessness with respect to 'things as they are,' born of personal observation, questioning and study, coupled with what we know as a result of our physical actions rooted in the world. It is precisely here, where the inner and the outer landscapes merge, that the desired perceptual shift takes hold. How is this so? Our capacity for creative vision is born of our ability to observe the 'facts' of the natural world the existence of things-in-themselves - and internalize them in ways that are personally and profoundly meaningful. Recognizing ourselves in nature gives us, then, the means by which we nurture this relationship. It is what ultimately allows us to love the world because we see ourselves in it. 


\section{Projects and initiatives}

With the objective of developing a means of creating measurable, landscapescale improvements in the health and resilience of forests and forest-dependent communities, Newforest Institute pursues its goals along multiple strands, each combining community-based approaches with rigorous, alternative research methods and data collection. For the past two years, Newforest has collaborated formally and informally with a wide variety of partners - from government agencies and universities to community and non-profit groups - in order to define some of the community's most pressing socio-economic and ecological issues related to the forest and forest resources. Through this iterative, collaborative process, we have developed the conceptual frameworks that underlie our main initiatives. Each of these initiatives is designed to catalyze systemic, long-term shifts in socio-economic, cultural and ecological well-being in traditionally forest-dependent communities, addressing the challenges of demographic diversity, increasing development pressures and persistent poverty in creating long-term, sustainable forest practices.

Underlying each project is the assumption that transformative education rooted in the weaving together of scientific knowledge, body knowledge and intuitive knowledge, coupled with a deepening awareness of ourselves as nature - has the capacity to effect real and measurable improvements in individual and collective health and well-being across the landscape. In partnership with the University of Maine and other academic partners, Newforest plays a unique role in developing innovative community-based processes for change. Through rigorous and innovative documentation and research design, these initiatives will make significant contributions to our understanding of the effectiveness of alternative approaches to sustainable forest management, community-based forestry, and processes of community engagement and change. Together, our projects address the challenges of demographic diversity, increasing development pressures and persistent poverty in creating long-term, sustainable forest practices and sustainable economic development. Our research is grounded in the recognition that, moving forward, a community's resilience urban and rural - will in large part be due to its capacity to form new and meaningful working relationships with each other and with the natural environment.

\subsection{Urban-rural youth forestry partnership: toward a new understanding of forest dependency}

This pilot partnership between Waldo County, Maine and Jersey City, New Jersey links children and land across natural/built and urban/rural boundaries in a collective, collaborative approach to community forestry. The program seeks to foster a deeper understanding of and appreciation for the connections of forest ecosystems across the landscape, incorporating permaculture and silviculture principals as well as native forestry practices across disciplines and grade levels. Our vision is: (1) a collective, collaborative approach across both districts, 
fostering in students a life-long love for the environment in general, and for their home landscape in particular; (2) schools that model for communities across the urban-rural spectrum a deep understanding of what it means to be forest dependent; (3) school districts that graduate high school students who, having experienced first-hand the long-term nature of land stewardship as an embedded part of their academic career, are prepared to act locally, regionally and globally out of a deep commitment toward sustainable social, economic, ecological and cultural solutions; and (4) students who grow in appreciation for the human community as an ecosystem, and for the roles that we all play in nurturing community here and further afield, creating an ever-widening connectedness across the urban-rural divide.

At base, the projects all seek to engage students and teachers in experiential learning opportunities as a regular part of their academic career. Moreover, we believe that only through the active exploration of the issues surrounding natural resource management are students able to appreciate the delicate balance between human needs and ecological sustainability. Permaculture - a design system for sustainable human habitat and perennial agricultural systems based on the relationships found in natural ecosystems - represents an opportunity for children to experience for themselves the ways in which we might reconcile the needs of the human community with those of the natural environment. Integrating the built world and the natural world, permaculture allows for a greater understanding of their interrelatedness. In addition, silviculture, as opposed to forest ecology, brings students into an active relationship with the forest in ways rarely included in school curricula. In addition to the development of a K-12 project-based curriculum and teacher training, projects thus far include: (1) project-based learning opportunities, such as permaculture gardens, food forests and forest projects at the schools and in the communities of Waldo County and Jersey City; (2) the Children's Forest, an ongoing collaborative stewardship project between high school students and the Town of Brooks, to complete a forest management plan for 90 acres of town-owned land as a Community Forest; and (3) plans for a Healing Forest in Jersey City.

Following on with the notion of the human community as an ecosystem, the Urban-Rural Youth Forestry Partnership allows us to effect landscape-scale change more specifically through the notion of the Healing Forest. The Healing Forest in Jersey City is a study in how nature in general - and forests in particular - can help heal people and communities and build a stronger, more effective educational system literally rooted in the world we live in. It will demonstrate our vision for a new urban landscape where forests can contribute: (1) to public health and safety, teaching people how to live with diversity, supporting each other, feeding themselves and others, providing medicine and space for healing and learning; (2) to public infrastructure by alleviating the stress of rain and waste water on a swampland covered in concrete; and (3) to climate and energy needs by providing clean air, shade, shelter and biodiversity. In the long term, we expect inner city children to reap the rewards of a new relationship with the earth and opportunities to learn by doing with their schools as well as their broader community. 
The research component of this project is essential to evaluate the effectiveness of bringing not only students but teachers as well into continual contact working with the forest, be it urban or rural. While there are metrics available to evaluate the effect of exposure to nature on academic performance and even emotional and physical health, it is difficult to transfer many of those metrics to a project-based learning situation. To that end, different forms of evaluating positive changes in both teaching and learning will have to be devised, including narrative reflection. Moreover, in addition to the traditional metrics of academic performance such as student test scores, we propose to include other measures such as graduation rates, suspension rates, and the prevalence of medication for attention deficit-related disorders and depression, as well as post-high school career choices and civic engagement. Furthermore, it would be important to develop the means to measure the effect of working with the forest through long-term stewardship, as it could be argued that one's awareness of oneself as part of the natural world grows differently through working with the land as opposed to the conventional (and often more intermittent) recreational/study forays into the woods.

\subsection{The Women's Earth Project: the opposite of poverty is beauty}

The Women's Earth Project is a community-based forestry project launched in the fall of 2008. The program seeks to reclaim two of the often neglected parts of the rural Maine landscape - rural, disadvantaged women and the poorly harvested forest parcels increasingly endemic to the region. By putting women in control of forest management on 250 acres of clear-cut Maine forestland, the Women's Earth Project seeks to create an alternative model for reconciling the social, economic, and physical well being of the human community with the long-term, multi-generational rehabilitation of degraded woods. Grounded in the notion that any intentional work of enduring transformation in socio-economic and even ecological systems is, in its essence, a public art project, such creative transformation begins necessarily with the self. Conceived in this way as a public art project, one goal of the Women's Earth Project is to create from the beginning a permanent work of art that symbolizes a strong sense of "home" in the forest - where resilience is nurtured; where the intuitive, feminine approach to healing and being healed by the forest is encouraged; and where a communitybased forest management project can be envisioned as public art. With its heightened and intentional use of the creative process, art is one of the most direct means of becoming adept at navigating one's inner landscape. Framing the Women's Earth Project as public art: (1) encourages, inspires and honors intuitive means of knowing the feminine voice that has been virtually silenced with respect to contemporary forest practices; (2) enables the women of the Women's Earth Project to trust and strengthen their intuitive muscle and their capacity for vision when it comes to working in the woods; and (3) harnesses art as a vital tool in creating a new language within the world of forest management and sustainability.

The ability to view one's relationship to the forest and forest management as art is particularly important in the context of low-income communities. In a 
cultural context which often equates wealth with income and worth with economic power, the ability to redefine one's self is an essential step toward personal transformation and arguably achieved most effectively through a heightened and intentional use of the creative process. Moreover, such selfredefinition ultimately has the ability to reset the parameters of the larger socioeconomic landscape within the community, for as Richard Florida [4] asserts "human creativity is the ultimate economic resource." Understanding one's work as art not only honors the intuitive practices attributed to the undervalued 'feminine' but also serves in this particular context to further the commitment and ties the participant women are currently constructing with each other and with the land. This collaboration and the forest health it will undoubtedly yield, will be a powerful reminder of the vitality of the community, illustrating the dynamic, healing force that comes about when disenfranchised members of a community are brought together and enlivened with the capacity to make positive and profound changes that impact the health and well-being of their community and their environment. The project will not only serve as a celebration of new ways for women to envision themselves as healing and intuitive forces within a forest community, but also represents an opportunity to show the rigorous contributions of the creative process to the discourses and practices of ecological, economic and cultural sustainability.

As a research project with both economic and silivicultural objectives, our goal is to evaluate the effectiveness of the Women's Earth Project as a community-based approach to improving the lives of rural low-income women and their families and communities, while engaging in the silvicultural rehabilitation of cutover, degraded forestland. Our objectives are threefold: (1) to evaluate the effectiveness of silvicultural rehabilitation and forest management as a supplement to current livelihood strategies for low-income women and children by tracking the socio-economic as well as physical and mental health benefits of community-based forest management on the lives of women, their families and their communities; (2) to evaluate the effectiveness of non-timber forest products (NTFPs) resulting from agroforestry, wildcropping and permaculture practices such as food forests to aid in the economic viability of long-term silvicultural rehabilitation of degraded forest parcels; and (3) to use ongoing research to inform and disseminate the strategies and improve the effectiveness of the Women's Earth Project, developing its potential as a replicable solution to achieving sustainable forestry practices in traditionally forest-dependent communities. We will test the hypothesis that bringing lowincome women and children, by and large marginalized from decision-making roles in forest management, into a working relationship with the land will produce measurable improvements across social, economic and ecological spectra, promoting the restoration of healthy forests and healthy communities.

\subsection{The Abundance Project: resource mapping and rethinking wealth}

The Abundance Project is designed to foster long-term, community-based dialogue and a radical re-thinking around the economy and natural resource use. Seeking to foster a new understanding of the health of rural communities and the 
values provided by forested landscapes, it means to serve as a model for building community consensus in rural areas, moving us closer to an economy that works in concert with human needs, desires and potential. At its core, The Abundance Project is about establishing value. Yet value does not simply mean the price of a good or service. Indeed, most elements of a forest cannot be sold or monetized. This does not mean, however, that the non-commercial components are valueless. For example, when a landowner chooses not to commercialize his or her forest, it must be that the 'revealed' value of a forest 'as is' must exceed its commercial value. Although intuitive in concept and practice, more concrete valuation of non-commercial features of the forest are essential for an individual as well as a community to weigh trade-offs and balance in their forest practices. Furthermore, in typically low-income, forest-dependent communities, the ability to map and value the range of forest and other ecosystem services, and to factor other less tangible 'products' such as physical and emotional health into the wealth equation, will allow communities to see more clearly the strengths and weaknesses in the collective fabric.

The project springs from the belief that jobs and environmental values are insufficient to ensure the conservation of U.S. forests. Vibrant, healthy rural communities providing rich opportunities - professional, cultural and recreational - through clearly understood and well-appreciated links to surrounding forests are needed if timberland is to remain intact and fully functioning. Such communities serve to attract and retain capable, motivated workers and also encourage landowners to keep forested parcels intact.

GPI Atlantic of Halifax, Nova Scotia, has been a leader in finding new ways to describe economic and social progress. Ron Colman, its Executive Director, argues that gross domestic product (the value of all the goods and services produced in an area) is an insufficient measure. He argues that there needs to be a qualitative element that brings in social welfare indicators to describe progress in a way average citizens can understand - by describing the kind of world we are creating for our children. Research by the USDA Forest Service suggests that forest landowners largely agree with Colman. In the latest inventory of the state's woodlands, USDA researchers [5] identified some 222,000 family forest owners who held 5.7 million acres (about a third) of Maine's 17.7 million acres of timberland. Unlike owners of 50 years ago, however, their reasons for investing in forestland are largely focused on non-economic values. Researchers reported that more than half of the family owners listed their main reasons for owning land as privacy, aesthetics, nature protection or 'family legacy.'

Most of the state's family forest owners are located in coastal and western Maine - areas experiencing increasing development pressure. In the 2005 report and in follow-up studies, the USDA Forest Service asserted that residential development - both primary residences and vacation homes - in south-central and southwestern Maine "will continue to increase in coming decades" [6]. "If residential development continues to expand in the case-study [Maine] watersheds... retention of land in forest use [will be] increasingly difficult." Furthermore, about 40 percent of those family forest owners are older than 65, and two-thirds are older than 55, according to the Small Woodland Owners 
Association of Maine. That means it is virtually certain that two-thirds of the state's family forest acreage (almost 2 million acres) will change hands in the next 25 years, even as the demand for that land is increasing rapidly.

The Abundance Project will ultimately formalize a framework for communities and individuals to map their natural and human resources, allowing them to evaluate the comprehensive impact of their actions in the forest. This understanding should prove critical for the sustained economic, ecological and spiritual health of forest-dependent communities. Based on the work of academic researchers, forest practitioners and community representatives, the documented work of The Abundance Project is intended to bring practical clarity to what has been by and large a murky interrelationship between revealed value in all of its dimensions and the forest.

\section{Global models and implications}

There is a growing awareness of the crucial role human transformation has to play in the health of the planet. Witness to this is the international ecovillage movement and the Global Ecovillage Network, as well as the worldwide spread of permaculture teaching and practices beginning with Bill Mollison in 1978 . Community forestry practices and research worldwide also point to the importance of the human-land relationship. In addition, there are increasingly attempts within academia to bridge disciplines even further afield, evidenced in the work of The Forum on Religion and Ecology. Nonetheless, the qualitative nature of the cultural and spiritual realms of human life has made them difficult to incorporate more rigorously into ecological and socio-economic studies. What remains a pressing task is to find ways to integrate more deliberately and more seamlessly our work on the inner landscapes into the critical research and practices of broad-scale restoration.

\section{References}

[1] Roszak, Theodore, The Voice of the Earth. An Exploration of Ecopsychology, Phanes Press: Grand Rapids, MI, p. 39, 2001.

[2] Ibid, p. 47.

[3] Ibid, p. 313.

[4] Florida, Richard, the Rise of the Creative Class, Basic Books: New York, p. xiii, 2002.

[5] Forests of Maine 2003, USDA Forest Service, pp. 5-13, 2005.

[6] Forests on the Edge, USDA Forest Service, pp 6-7, 2005. 